\title{
OBINO (Onet Binomial Nomenclature)
}

\author{
Rahmayani, Muhammad Romario Basirung
}

\begin{abstract}
This research is to develop interaction between Onet Game users with easy to understand the Binomial Nomenclature (BI) form OBINO (Onet Binomial Nomenclature) in supported education applicable. OBINO an android application that integrated with used Artificial Intelligence (AI) educational game can used to increase the storage capacity in the human visual memory in relation to understand the BI. OBINO expected to obtained as an integrated education game app on smartphone as a media support learners and knowledge of public understand BI. This application is expected to used extensively by the community so that new alternative to use of technology in education and future. This research is $\mathrm{RnD}$, developed the Onet Game as a study learning. When the application is completed, next to installed application on smartphone. The final step included a functional check to determine whether all the available fatures to function properly based on methods of AI game applications.
\end{abstract}

Keywords-Artificial Intelligence, Binomial Nomenclature, Onet Game, Smartphone.

\section{INTRODUCTION}

\section{A. Background}

Biology is the one of the lesson that have many terms. One of the biological terms that are often used for educational purposes is Nomenclature in Latin or Binomial Nomenclature in flora. This Binomial Nomenclature is one of the subject that contains of the scientific names of plants that learn began in Junior High School. This Nomenclature is usually a task to be controlled with appropriate levels at the school level. The mastery of this Nomenclature tend to be difficult, because the difficulty to pronounce the scientific names in plants and the length of the plant's name.

In understanding the meaning of the Latin language, commonly used tool is the dictionary. Dictionaries are available in print or electronically are not accompanied by a communicative interface or display so that visual function cannot be used well. Communicative Display provide a good stimulation of the visual storage memory in the human brain. Such benefits can be encountered as the development of applications that support the patterns of interaction between humans and devices that provide features that are more attractive, effective and efficient in its use by the public.

These features are interpreted through the methods of Artificial Intelligence (AI) that is integrated in the application development platform that can follow people's needs. One of

\footnotetext{
Rahmayani, State University of Makassar, Indonesia, rahmayanibio@gmail.com

Muhamamad Romario Basirung, State University of Makassar. Indonesia romariobasirung@gmail.com
}

the most commonly used platform application developers is based on android platform. Android supports fully programmers to create or develop applications through the ease of inputting script and its relation to the application display more varied. Variations see options for building applications through Android platform supports the user ease of application. Android app users can take advantage of the ease and availability of features for the more varied in supporting the ability of the public in using technology, especially the use of smartphones.

The use of smartphones today is not limited to the ease of communication, but can be used for activity-based creative economy, a provider of public information, multimedia and aspects of life related to entertainment. One of the entertainment media that has been developed and collaborated to support the improvement of education is the game. Games available online and offline. Unlike the online games that need to support the availability of the Internet network to be used, it can be used offline game is portable or can be used anywhere and anytime and still be able to support the attraction factor in the game after being used several times. Attraction factor is one of them contained in Onet game. Onet game is a game that has been supporting the attractive interaction between the user and the application itself, so users can be encountered almost in all age levels ranging from children, adults to the elderly.

In relation to support the improvement of education applicable, the author has a project to develop the interaction between users of the Onet game with ease of understanding the nomenclature Binomial Nomenclature in the form OBINO (Onet Binomial Nomenclature) which is an application that integrates with android using Artificial Intelligence shaped educational games that can be utilized to increase the storage capacity in the human visual memory in relation to understanding the nomenclature Binomial Nomenclature. The author intends to provide convenience to the students or the general public to understand the nomenclature Binomial Nomenclature by utilizing the android based applications more attractive and communicative.

\section{B. Problem Statement}

Issues that will be examined is how to apply the methods of Artificial Intelligence (AI) in making applications OBINO (Onet Binomial Nomenclature) based on Android that can be used learners and the general public to make it easier to understand the Binomial Nomenclature?

\section{Purpose}

The purpose of making the application OBINO (Onet Binomial Nomenclature) is applying Artificial Intelligence (AI) methods on Android-based gaming applications as a 
substitute for a dictionary in supporting the ability of learners and the general public to make it easier to understand the Binomial Nomenclature.

\section{Significance of The Research}

OBINO (Onet Binomial Nomenclature) expected to be obtained as an integrated educational game app on a smartphone as a media support learners and knowledge of the public understand the Binomial Nomenclature. This application is expected to be used extensively by the community so that a new alternative to the use of technology in education and the future.

\section{E. Benefit}

OBINO (Onet Binomial Nomenclature) developed is expected to be more educative gaming applications to make it easier to understand the Binomial Nomenclature. Application of this game can be a pioneer and indicator applications development and use of technology for education better.

\section{II.LITERATURE REVIEW}

The procedure for naming the living things based on the method Binomial Nomenclature by Carolus Linnaeus. Binomial Nomenclature means the naming of the two words. So all living creatures given names that consist of two words of Latin, for example, the scientific name of rice is Oryza sativa L. plants. Binomial Numenclature is used to classify living things based on certain criteria that will facilitate and contribute to the development of science. Indirectly learners and the general public will be required to understand the Nomenclature. One way to understand it is to use the scientific name dictionary available in print or electronically. The development of electronic media participate and support the development of science as more applicative methods of artificial intelligence (artificial intelligence) that is integrated on the smartphone.

According to Wijaya (2013), Artificial Intelligence (AI) itself raised by a professor from the Massachusetts Institute of Technology named John McCarthy in 1956 at Dartmouth Conference, attended by AI researchers. This application models the human thought process and design of machines that can mimic the human behavior. The concept of search-based search first widen (Breadth-First Search) as well as in-depth first search (Depth-First Search). There are some applications that use these:

1. Game Board and puzzle (tic-tac-toe, cheese).

2. Schedeule and routing problem (travelling salesman problem).

3. Parsing language and its interpretation (structure and meaning).

4. Logic programing (searching for fact and implication).

5. Computer vision and introducing pattern.

The application of this method can be encountered at some games that are supported and developed using android. Concept of Android since its inception as a software-based distributed computer code (Open Source) and free. The advantage of open source, many software developers are able to see and take advantage of the code and can make or create new applications in it. So that developers have full access to the same framework APIs used by the core applications. The application architecture is designed so that components can be reused (reuse) with ease. This same mechanism allows components to be replaced by the user. One of the products of android that is often used is the onet game. Onet Game is made using the system Graphical User Interface (GUI) in android. The programming language used in the making of this application is a Java-compatible.

Onet Game which was introduced in 2001 and has reached version 5th in 2005 then we'll modify. Modifications of this Onet game then try built and applied in relation to support and facilitate the understanding Binomial Nomenclature with gaming applications OBINO (Onet Binomial Numenclature). OBINO is an integrated educational game app on a smartphone as a media support learners and knowledge of the public understand the no Binomial Numenclature.

\section{Methodology}

\section{A. Type of Research}

The type of research is Research and Development (RnD) because developed the Onet game as a study learning.

\section{B. First Stage}

At this early stage are doing is reviewing all the literature related to the project, such as looking for methods of Artificial Intelligence that will be applied and determine the type of android platform that supports the application. After getting the specification right, next is Mockup Balsamic preparations for their software to design the layout and final application for doing preparation. Eclipse software coding that integrate the script with android platform.

\section{Second Stage}

The activities at this stage is the implementation of the initial design making use Balsamic Mockup software is then integrated on android platform through coding using Eclipse software based on artificial intelligence methods to determine which features are needed. Once the application is complete, the next is to install the application on the smartphone or ipad android.

\section{Final Stage}

At the final stage, a functional check performed to determine whether all the available features to function properly based on the methods of artificial intelligence gaming applications. When all the features to function properly, then the next game applications tested on students at partner schools. 


\section{E. Implementation Step}

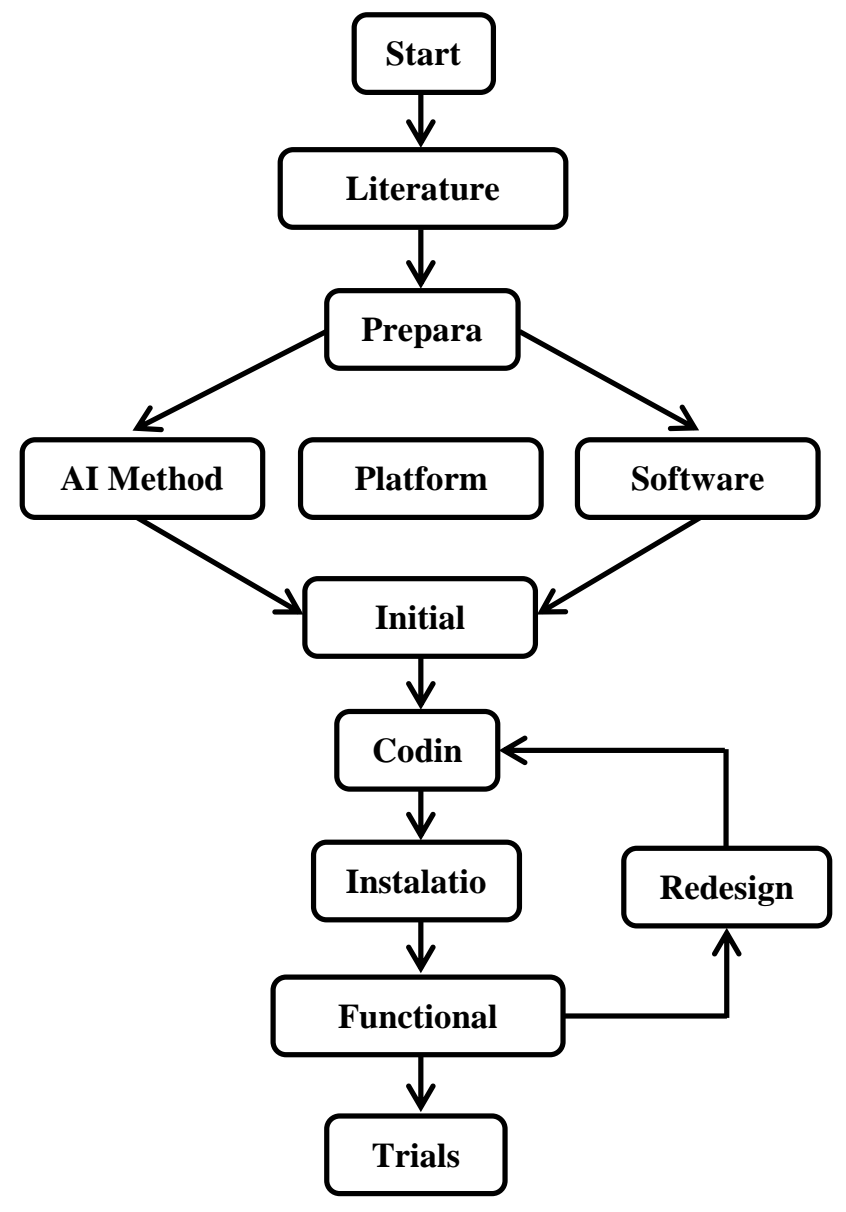

IV. RESUlt AND SPECIFIC Potential

The results achieved after the implementation of several stages of implementation starting from the initial stages to the end, at this stage acquired Artificial Intelligence methods and platforms that are applied to the application. The method is applied through the development of gaming applications using Flash CS6 with the main view of the game as follows:

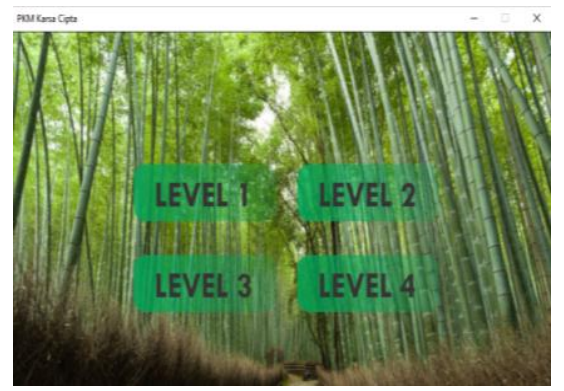

Fig. 1: OBINO have four levels

These features are used to simplify the user further divided into 4 Level games to improve the ability to understand the Binomial Nomenclature according OBINO with the appearance of each level as follows:.
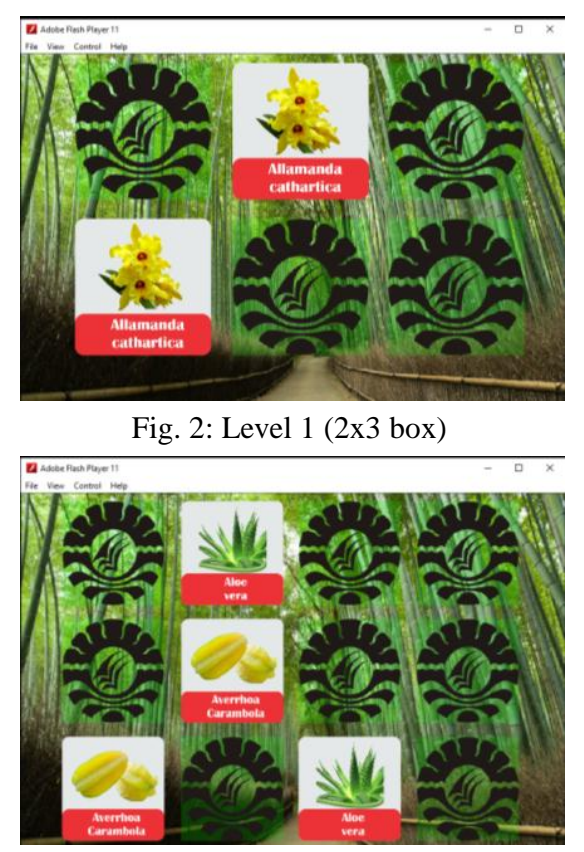

Fig. 3:Level 2 (3x4 box)

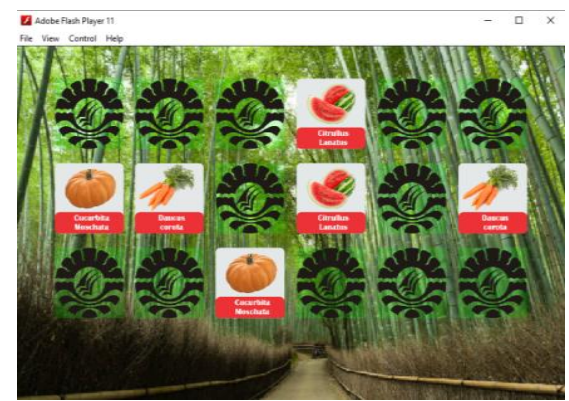

Fig. 4: Level 3 (3x6 box)

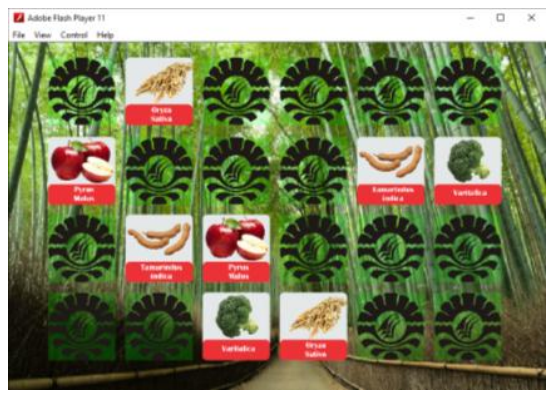

Fig 5: Level ( $4 \times 6$ box)

\section{V.CONCLUSION AND RECOMMENDATION}

\section{A. Conclusion}

OBINO (Onet Binomial Nomenclature) which is an educational game can be completed after going through several stages of the manufacturing method on a platform Artificial Intelligence Flash CS6. OBINO consists of five (5) main parts namely the part to choose the level of the game with some other features. These features are used to simplify the user further divided into 4 Level games to improve the ability to understand the Binomial Nomenclature. 


\section{B. Suggestion}

Student Creativity Program had implemented with the title "OBINO (Onet Binomial Nomenclature)" with a partner Junior High School 26 Makassar still need some evaluation and improvement of the quality of some features associated by Educative Game. So organizers advise to do improvements platform with a better preface.

\section{REFERENCES}

[1] Wijaya, Edi. 2013. Analisis Penggunaan Algoritma Breadth First Search dalam Konsep Artificial Intelligencia. Jurnal Time: 2 (2): 18-26. 